\title{
SWOT analysis of the Institute of Meteorology and Water Management - National Research Institute in the context of World Meteorological Organization Reform adopted during its $18^{\text {th }}$ Congress
}

Tomasz Walczykiewicz

Institute of Meteorology and Water Management - National Research Institute, Podleśna 61, 01-673 Warszawa, Poland, e-mail: tomasz.walczykiewicz@imgw.pl

Janusz Filipiak

University of Gdańsk, Faculty of Oceanography and Geography, Jana Bażyńskiego 8, 80-309 Gdańsk, Poland

\section{Abstract}

This article is an analysis of how the World Meteorological Organization (WMO) constituent bodies governance reform (WMO Reform) can affect the activities of the Polish National Hydrological and Meteorological Service. The analysis employs the SWOT (Strengths, Weaknesses, Opportunities, Threats) model. The World Meteorological Congress is the highest authority of the World Meteorological Organization, whose findings guide the operations of the WMO and the National Meteorological and Hydrological Services (NMHSs) globally. During the $18^{\text {th }}$ Congress, in June 2019, discussions covered the routine operations of the WMO and its Secretariat, the status and development prospects of all the Organization's research and technical programs, and the Organization's budget for the $18^{\text {th }}$ financial period beginning in 2020. The key actions of the Congress, however, were the election of the WMO senior officers and final approval (after thorough discussion) of the WMO Reform of its governance structure. The purpose of the Reform is to ensure better preparation of the organization for the challenges of the present and future, such as climate change and its impact, the growing number and intensity of extreme weather events, environmental degradation, and increasing urbanization. The tasks of the National Hydrological and Meteorological Service in Poland are performed by the Institute of Meteorology and Water Management - National Research Institute (IMGW-PIB), in accordance with the provisions of the Water Law.

Keywords

Meteorology, hydrology, WMO, reform, analysis.

Submitted 3 February 2020, revised 20 April 2020, accepted 29 June 2020 DOI: $10.26491 / \mathrm{mhwm} / 124787$

\section{Introduction}

The World Meteorological Organization (WMO) is an intergovernmental organization of 193 members based in Geneva. It was established in 1950 as a transformation of the International Meteorological Organization (IMO) that had been founded in 1873. The treaty establishing the organization was signed on October 11, 1947 (Convention 1947), and took effect on March 23, 1950. In commemoration, this date is celebrated annually as World Meteorological Day. Since March 17, 1951, WMO has been a specialized agency of the United Nations with the mission to standardize, improve, and exchange meteorological information and to support climatological, hydrological, oceanographic, and environmental studies. The main task of the WMO is to organize and coordinate the activities of meteorological services of various countries, by unifying meteorological observation methods and disseminating weather forecasts. Every four years the World Meteorological Congress, the WMO’s supreme governing body, meets in Geneva. Its findings guide the operations of WMO and the National Meteorological and Hydrological Services 
(NMHS) throughout the world. During the $18^{\text {th }}$ Congress in June 2019, routine topics of discussion included the operations of the WMO and its Secretariat, the status and development prospects of all the Organization's research and technical programs, and the Organization's budget for the $18^{\text {th }}$ financial period beginning in 2020. The key points of the Congress, however, were (1) the election of the WMO Secretary General, President, three Vice-Presidents, and members of the Executive Council for new four-year terms of office; and (2) a final thorough discussion and approval of the WMO constituent bodies governance reform (WMO Reform). The Reform is intended to ensure better preparation of WMO and its members and their National Hydrological and Meteorological Services for the challenges of the present and future, such as climate change and its impacts, the growing number and intensity of extreme weather events, environmental degradation, and increasing urbanization.

Poland, one of the founding members, has belonged to the WMO since 1947. The tasks of the National Hydrological and Meteorological Service in Poland are performed by the Institute of Meteorology and Water Management - National Research Institute (IMGW-PIB). The statutory responsibility of the IMGW-PIB is to monitor atmospheric and hydrological processes with sufficient coverage to support forecasting and early warning of threats to public safety, health, and life of citizens and property. The agency also conducts long-term, complex research in the areas of meteorology, hydrology, water management, and oceanography, directed toward steady improvement in forecasting complex atmospheric and hydrological phenomena and their consequences. IMGW-PIB also monitors Poland's climate. Under the Water Law Act (July 2017) this institution includes the National Meteorological \& Hydrological Service (PSHM). As a result, it maintains the national observational-measurement network, the data exchange and archiving system, as well as meteorological and hydrological forecasting offices. Meteorological and hydrological monitoring is financed principally from the state budget. An interesting question is how the WMO Reform is likely to affect the activities of the Polish NMHS.

\section{Tasks of the Institute of Meteorology and Water Management - National Research Institute, within the framework of WMO}

The tasks of the IMGW-PIB include meteorological and hydrological measurements and observations conducted through the observational network, including:

a) 63 synoptic stations;

b) 200 climatological stations (including evaporation measurements);

c) 659 precipitation stations;

d) 862 water gauge stations (including coastal, limnological, and hydrometric measurements);

e) 3 aerological measurement stations;

f) POLRAD meteorological radar network, which consists of 8 radar stations;

g) PERUN lightning detection and location network consisting of 12 stations;

h) satellite data assimilation station;

i) additional dedicated measurement networks, i.e. 23 evapotranspiration stations, 9 radiation stations, radioactive contamination measurements, etc. 
The above measurements and observations are carried out continuously, to the extent and with the frequency appropriate for a given type of station, as specified by WMO standards as well as regulations and methodologies used in PSHM. The basic tasks of PSHM also include maintenance, ongoing repair and failure removal, servicing and reconstruction, expansion, reconstruction, and disassembly of the basic measurement and observation network as well as a system for collecting, processing, and exchanging data.

Real-time analyses of the hydrological and meteorological situation are carried out, supporting preparation and dissemination of forecasts and warnings. Additional important tasks are to prepare meteorological and hydrological information, bulletins, hydrological and meteorological yearbooks of PSHM, as well as other dedicated assessments. All these tasks are carried out by closely cooperating meteorological and hydrological forecasting offices and supporting teams.

In preparing forecasts, the Institute uses, among others, the COSMO${ }^{1}$ and $\mathrm{ALADIN}^{2}$ models, participating actively through its representatives in the work of these consortia. Activities related to hydrological and hydraulic modeling in the field of flood hazards and drought assessment are part of the EU's water policy context (Directive 2000/60/EC). Optimal cooperation of PSHM with public administration bodies in reducing the effects of dangerous phenomena occurring in the atmosphere and the hydrosphere, in turn, requires conducting educational activities in the field of hydrology, meteorology, and oceanology. These activities are aimed at increasing the effectiveness of hazard protection. The development of PSHM is supported by appropriate IMGW-PIB methodological departments. To ensure the data exchange and access required for hydrological and meteorological protection, IMGW-PIB belongs to other international organizations such as EUMETSAT ${ }^{3}$, EUMETNET $^{4}$ and ECOMET ${ }^{5}$. It should be emphasized that from the point of view of state policy it is important in Poland that meteorological and hydrological protection is provided jointly by the same institution, which is neither global nor pan-European. In other large European countries like Spain, Germany, and France, these tasks are divided between different institutions. From the point of view of WMO reform, the Polish solution is important and can be treated as an advantage.

\section{Basic directions of WMO Reform}

\subsection{The main achievements}

The WMO Strategy for 2020-20236 captures the WMO future activities in the form of five Long-Term Goals (LTG) described as follows:

- LTG 1. Better serve societal needs.

- LTG 2. Enhance Earth system observations and predictions.

\footnotetext{
${ }^{1}$ www.cosmo-model.org

2 www.umr-cnrm.fr/aladin/

${ }^{3}$ www.eumetsat.int

${ }^{4}$ www.eumetnet.eu

${ }^{5}$ www.ecomet.eu

${ }^{6}$ https://www.wmo.int/aemp/sites/default/files/d06 Att1_wmo-sp-2020-2023-scheme-29-Nov-2017.pdf
} 
- LTG 3. Advance targeted research.

- LTG 4. Close the capacity gap.

- LTG 5. Strategic realignment of WMO structure and programs.

Simplifying, the first three goals are dedicated to the development of the following domains: services, infrastructure, and science. The fourth objective refers to regional aspects, while the last one concerns further systematization and improvement of the effectiveness of WMO operations. The implementation of the Strategic Plan will be carried out by means of an Operational Plan, which describes in detail the allocation of budget funds for specific projects.

The WMO Congress approved, after detailed analysis, all final guidelines that had been forwarded in the previous months by the Executive Council, in particular the Working Group on Strategic Planning and the Task Force on Reform. The debate on the final shape of the Reform lasted until the last day of Congress, as the scale of planned changes generated many uncertainties, and sometimes even imperfections requiring refinement during the Congress's activity.

The finally-approved Reform of the WMO affects each of its constituent bodies. Only the geographical division into six associations has been virtually unchanged, but their tasks have been thoroughly reformulated in ways that significantly improve the concentration and distribution of resources allocated to tasks at regional and sub-regional levels.

In reference to the new management structure and strategic plan, in line with the WMO Reform approved, the existing eight WMO Technical Commissions have been replaced by two more coordinated commissions to streamline work and maximize the effects of their activities.
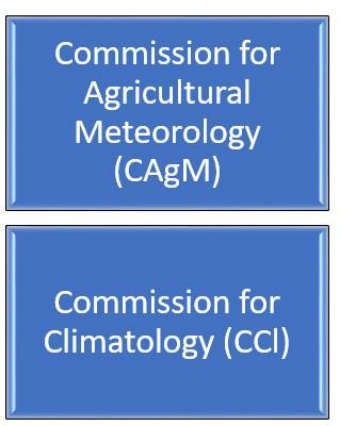
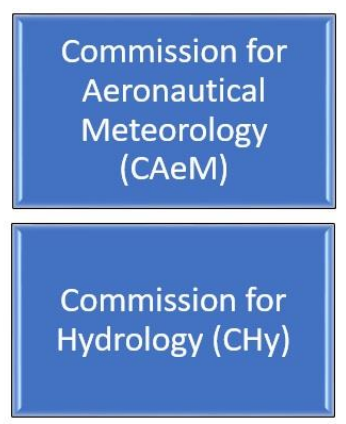
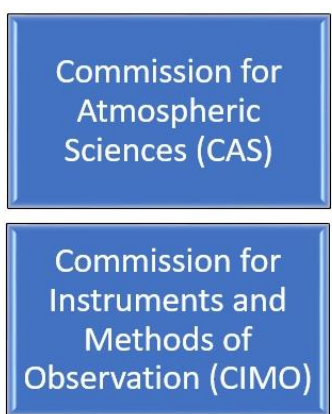

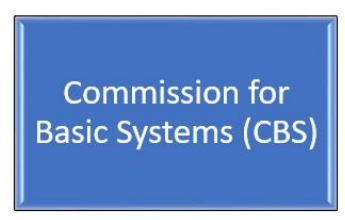

Commission for

Oceanography and

Marine

Meteorology

(JCOMM)

Fig. 1. Former WMO Technical Commissions.

The Commission for Observation, Infrastructure and Information Systems is intended to contribute to the development and implementation of globally coordinated systems for the acquisition, processing, transmission, and dissemination of Earth system observations and standardization related to each stage of this value chain (meteorological and hydrological value chain). This Commission was also entrusted with coordinating the production and use of forecasting models as well as developing and implementing good practices of data and information management for all WMO programs and related areas of application and services. 
The Commission for Weather, Climate, Water and Related Environmental Services and Applications will contribute to the development and implementation of globally harmonized weather-related services and applications to climate, water, oceans, and the environment to enable informed decision-making and the realization of socio-economic benefits by all end-user groups in society.

The WMO Executive Council (EC) will invariably take care of all the work related to the coordination of activities of individual newly-appointed WMO constituent bodies and will ensure the development and control of mechanisms for effective cooperation between them. All new bodies will be subordinate to the EC (or cooperate with it). The organization of this process will be assisted by its Technical Coordination Committee (TCC), which includes: presidents and vice presidents of technical committees, presidents of regional associations, head of the Research Council, and heads of programs sponsored and co-sponsored by WMO.

The Research Board will translate WMO's strategic goals and decisions of the Congress and EC into overarching research priorities, and ensure the implementation and coordination of research programs. The Scientific Advisory Panel (SAP) will, in turn, develop opinions and recommendations for Congress and the EC on matters relating to WMO research strategies and optimal scientific directions to support the development of the organization's mandates in the fields of weather, climate, water, and related environmental issues, such as social aspects. The $\mathrm{EC}$ was composed of representatives primarily from the meteorological community. The SAP, in turn, is a group of independent scientific authorities with internationally recognized status.

The diagram of the new WMO organizational structure, including Long Term Goals is shown in the figure below.

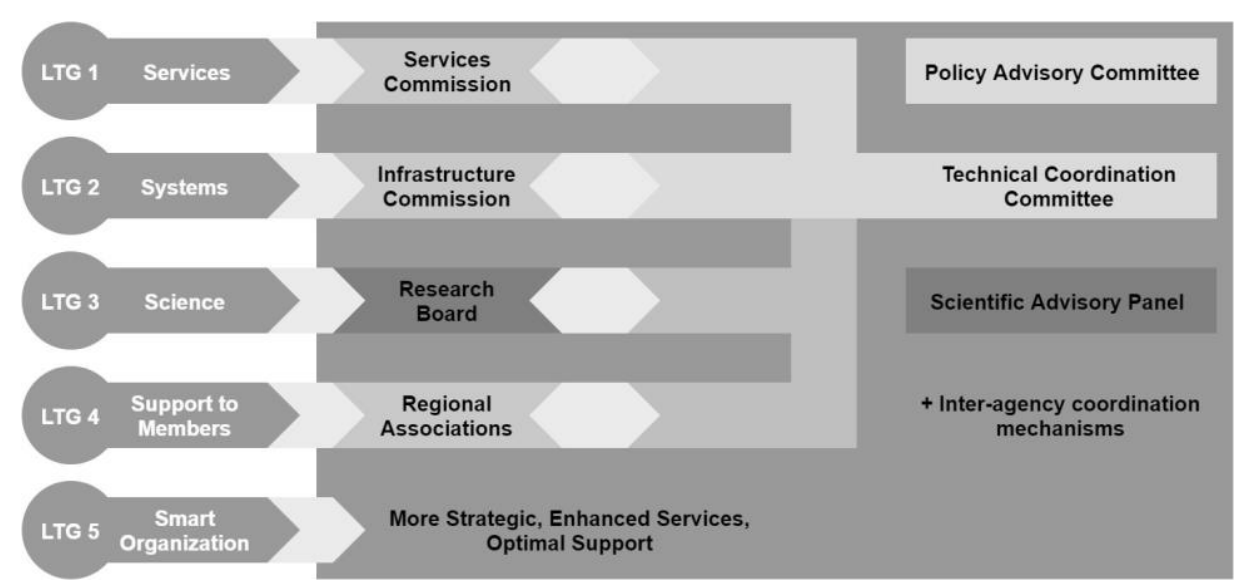

Fig. 2. The new WMO organizational structure (adapted from WMO documentation).

The Joint WMO-IOC Collaborative Board (IOC: UNESCO’s Intergovernmental Oceanographic Council) will in turn coordinate the joint development, integration, and implementation of activities related to oceanographic and meteorological observations at sea, data management and information, services, modeling and forecasting systems, as well as research. Several activities formerly coordinated by the JCOMM 
(Joint WMO and IOC Committee on Oceanography and Marine Meteorology) have been transferred to the newly established WMO technical commissions.

The Policy Advisory Committee (PAC) is a group of selected EC members as well as SAP and TCC heads, which, under the direction of the WMO President, is to shape the vision of developing the organization's political and financial strategies. The Policy Advisory Committee (PAC) shall advise the EC on any matters concerning the strategy and policy of the Organization submitted to it by the EC.

WMO, in the context of the Reform, is beginning to attach much greater importance to: (1) strengthening the coordination of actions combating the effects of global climate change; (2) improving operational hydrological services; and (3) improving monitoring and forecasting of hydrological phenomena. Two groups were established under the EC to coordinate these activities: a Climate Coordination Panel and a Hydrological Coordination Panel.

The Hydrological Assembly, which was first convened during the $18^{\text {th }}$ Congress, will become a regular event accompanying every Congress. It is intended to be a forum for exchanging views among Hydrological Advisers of Permanent Representatives of WMO countries.

\subsection{Hydrology}

A special dialogue on water during the EC-70 in June 2018 and an extraordinary Commission of Hydrology (CHy) session in February 2019 were the first steps toward a consensus about how best to manage hydrological affairs in the reformulated WMO. The Hydrological Assembly held during the Congress led to consolidated views on how to engage the wider community and strengthen cooperation with partners. The Assembly also developed ways to organize hydrological activities more effectively in WMO and to increase participation of the hydrological community in the new WMO governance structure. The discussions resulted in formulation of eight long-term ambitions that will inform the development of waterrelated WMO activities. These include: (1) no one is surprised by a flood; (2) everyone is prepared for drought; (3) climate and meteorological data support the food safety program; (4) high-quality data supports learning; (5) science provides a solid foundation for operational hydrology; (6) we have thorough knowledge of the world's water resources; (7) sustainable development is supported by hydrological information; (8) water quality is known. These ambitions are expected to lead to increased involvement and participation of a broad hydrological community in WMO activities to improve knowledge-based decision making.

During the Assembly, the discussion panel 'Hydrology for sustainable development and peace' concluded with the following findings:

1. Water is a key factor for life, environmental protection, and sustainable development.

2. Several stressors affect the water cycle, affecting water resources distribution and availability, which are especially sensitive to climate change, population growth, and water quality.

3. The UN system lacks one strong political voice for water, and WMO should take a more active coordination and leadership role, focusing on its mandate in operational hydrology. 
4. There is market potential for extending hydrological data and services. WMO can contribute to achieving a balance between specific needs and general social interest.

5. The collection, management, and sharing of data is essential for the development of relevant hydrological products.

6. Data and knowledge are of fundamental importance in the decision-making process, especially in international and transboundary waters.

7. Water quality and quantity issues should be addressed in a comprehensive manner.

8. A dialogue with all users is necessary to articulate their needs, discuss them, and then include them throughout the entire value chain.

An extremely long discussion was undertaken to redefine the concept of operational hydrology. The consensus definition is as follows: "Operational hydrology is the regular measurement, collection, processing, archiving and distribution of hydrological, hydrometeorological and cryospheric data in real-time as well as generating analyses, forecasts and warnings that inform about water resource management and support water-related decisions across the entire spectrum of time and spatial scales. Operational hydrology requires capacity building and scientific and technical progress and innovation in the areas of observation, standards and data services, modeling, prediction, hydro computer science and decision support, training and information activities." The annotation to the definition states that "this data includes, inter alia, precipitation; air temperature and humidity; water levels of streams, lakes, deltas and estuaries; flow; snow and ice cover, water equivalent; river and lake ice; glacier mass balance; reservoir reserves; soil moisture; groundwater and ground freezing; evaporation and evapotranspiration; water temperature; sediment dynamics; water and sediment quality and other related variables, including in the context of global change. Global change is expressed in various aspects, such as land-use change, socio-economic dynamics, climate variability and changes at various scales".

\subsection{Climatology}

Upon the failure of the Global Framework for Climate Services ${ }^{7}$ management structure, Intergovernmental Board for Climate Services (IBCS), it became necessary to reformulate this body with a new, much more effective mechanism. For this reason, it was decided to establish a fairly wide Climate Coordination Panel (including representatives of associations, IPCC, technical committees, PACs, and the Research Council), which, under the leadership of the First Vice President of WMO, will review the extensive WMO activities related to climatological issues.

A preliminary version of the Manual on High Quality Global Data Management Framework for Climate was adopted. It is an annex to the Technical Regulations (basic WMO documentation on standard and recommended procedures), which is to enable national services to effectively develop and exchange highquality climate data based on integrated infrastructure at global, regional, and national levels. Based on that document, the assumptions of the open-source reference system for climate and hydrological data man-

\footnotetext{
7 https://gfcs.wmo.int/
} 
agement will be built on the basis of proven climate data management practices (specifically the Climate Data Management System described in WMO No. 1131). The long-term observing stations initiative is being continued and 23 additional stations were added to the current 117 stations. It may be important for the Polish service to submit several candidates from Polish stations.

The Congress adopted a methodology for cataloging dangerous meteorological phenomena, recommending the services to adapt it in their work on cataloging and archiving data. The results of the methodology test phase in RA VI confirmed the great utility of the method.

\subsection{Meteorology}

The Congress focused on various initiatives related to meteorological applications. In the field of general meteorology, WMO's unchanging vision of development of the Impact-Based Forecast and Warning Systems should be emphasized.

An important item on the agenda was the adoption of several interdependent concepts: GMAS (Global Multi-Hazard Alerting System 8 , WCM (WMO Coordination Mechanism) and SWFP (Severe Weather Forecasting Program), which will provide support from WMO for the development of a global information system on hazardous phenomena, which in turn will improve the coordination of humanitarian operations conducted by United Nations agencies, especially in the poorest countries. Although the European Meteoalarm managed by EUMETNET under the EMMA ${ }^{9}$ program is cited as an example, GMAS is planned as a warning system for many threats, not only from the weather. The implementation of GMAS is also an opportunity to emphasize the irreplaceable role of national services in issuing alerts (the socalled single authoritative voice). It was recommended that Technical Committees develop guides to the procedures and mechanisms for effective support from national services of the national disaster risk management system, with emphasis on: institutional coordination in the areas of risk information and impact assessment; detection, monitoring, analysis, and forecasting of hazards and possible consequences; disseminating warning and advisory information and supporting national response and recovery plans. The WMO long-term plan for the development of aviation meteorology was accepted, which coincided with the assumptions of the future operation of ICAO, expressed in the GANP (Global Air Navigation Plan) (ICAO 2016) document.

\subsection{Oceanography}

In view of the approaching Decade of Ocean Knowledge for Sustainable Development 2021-2030 announced by the United Nations (UN Decade of Ocean Science for Sustainable Development), the Congress adopted the principles of a framework of close cooperation with UN agencies, international organizations, governmental institutions, the academic community, and the private sector. The provisions of the framework refer to five specific tasks posed to this cooperation: (1) construction of advanced deep ocean observation systems, (2) implementation of new technologies in ocean biochemical measurements, (3)

\footnotetext{
${ }^{8}$ www.wmo.int/gmas/

${ }^{9}$ www.eumetnet.eu/activities/forecasting-programme/current-activities-fc/emma/
} 
concentration of ocean models resolution, (4) new methods for assimilating coupled data, and (5) conducting focused observation and modeling campaigns. Member State services were called upon to adopt and implement the provisions of all resolutions related to the marine environment. Member State services have been encouraged to actively support the United Nations Ocean Conference 2020 event in February 2020 in New York.

\subsection{Observation, transmission, and processing systems}

The key WMO initiative, WIGOS-WMO Integrated Global Observing System (IMGW-PIB 2016) is entering a fully operational phase. The Congress acknowledged that despite significant financial and technical problems, WIGOS has reached a sufficient level of maturity that it can be recognized as operational on January 1, 2020. At the same time, WIGOS is becoming part of the basic structure of WMO's operations. The priorities of the operational phase include slightly modified terms, with the following status indicated for the pre-operational phase 2016-2019:

1. National implementation of WIGOS;

2. Supporting a culture of compliance with WIGOS technical regulations;

3. Implementation of GBON(Global Basic Observing Network ${ }^{10}$ and RBON(Regional Basic Observing Network);

4. Operational implementation of the WIGOS data quality monitoring system;

5. Operationalization of WIGOS Regional Centers;

6. Further development of OSCAR (Observing Systems Capability Analysis and Review Tool) ${ }^{11}$.

\section{SWOT analysis in the context of the World Meteorological Organization Reform}

SWOT analysis is used to analyze the internal and external environments of an organization, as well as to analyze a project or business approach. It is used universally as a tool for the first stage of strategic analysis. It supports use of available information to develop an action strategy based on strengths and opportunities, while eliminating or reducing weaknesses and threats (Szałata, Zwoździak 2011).

SWOT analysis consists of dividing information into four groups:

- $\mathrm{S}$ (Strengths) - everything that is an asset or advantage;

- W (Weaknesses) - everything that is a weakness, barrier, or defect;

- O (Opportunities) - everything that creates a chance for favorable change;

- $\mathrm{T}$ (Threats) - anything that creates a danger of adverse change.

Strengths, weaknesses, opportunities, and threats of IMGW-PIB in the context of World Meteorological Organization Reform are identified below. They were classified according to their impact on IMGW-PIB as either $1=$ weak impact, or $2=$ strong impact.

\section{Strengths}

${ }^{10}$ www.wmo.int/pages/prog/www/wigos/GBON.html

${ }^{11}$ www.wmo-sat.info/oscar/ 
- Joint solution and unified structure

The advantage of the Polish approach to the field of hydrological and meteorological services is the combination of tasks in the fields of meteorology, hydrology, to some extent oceanography, meteorological protection of civil aviation, and research into a single institution. This allows for better coordination of work, economic efficiency, and better management of the joint technical service (2-strong impact).

- Hydrology and water resources are included in the activity

Before the Congress, there was great concern about the fate of hydrology at WMO in connection with the reorganization plans and the liquidation of the hydrology commission. It was thought that the liquidation of the hydrology commission would lower the rank of hydrology in WMO and would hinder cooperation in the field of hydrology in the fields of measurement, modeling, and forecasting. Meanwhile, the Commission for Weather, Climate, Water and Related Environmental Services and Applications will have a broad scope in its competencies that also provides water services. In this respect, the role of hydrology is to create analyses for integrated water resources management, taking into account their quantity and quality. In this regard, IMGW-PIB also maintains methodological departments for the study and research of water resources. This solution should be used as a potential opportunity in the WMO activity forum (2strong impact).

- Cooperation in Disaster Risk Reduction (DRR)

The successful contribution of WMO to disaster risk reduction ${ }^{12}$, climate change adaptation (CCA), and increased resilience is based on coordinated and collaborative initiatives between the WMO Members. It should be emphasized that in addition to its statutory activities, the Polish NHMS, IMGW-PIB actively participates in complementary work focusing on reducing the risk of natural and technological hazards. The main directions include: (1) National Platform for Disaster Risk Reduction at IMGW during the Hyogo decade (Hyogo 2007); (2) training and education policy; (3) completed research and implementation projects.

IMGW-PIB recording and statistics of emergency alerts supports the observation that the number of extreme weather events dangerous to human health and life and the material losses associated with them is greatly increasing. The Institute of Meteorology and Water Management - National Research Institute, participates in the process of identification of meteorological and hydrological risks and hazards, analyses of these threats, and distribution of warnings about their possible occurrence. IMGW-PIB is a good example of a broader involvement of the national hydrometeorological service in activities to reduce natural and technological hazards. In this regard, it may also be part of the WMO forum, which is actively involved in DRR aspects (1-weak impact).

- Research activities 
In addition to activities related to the tasks of the National Hydrological and Meteorological Service, the Institute also conducts scientific research that provides significant support in the development of this institution.

IMGW-PIB scientific and research and implementation work focuses on the following problems:

In the field of bydrology - developing modern computer models for forecasting water flows in mountain rivers and streams, with particular emphasis on flood and low-pressure conditions; assessment of the size and variability of surface water resources over time under the influence of climatic and anthropogenic factors; study of hydrological processes in small experimental and representative catchments.

In the fields of meteorology and climatology - improving numerical methods for meteorological and agrometeorological forecasts; the use of remote sensing, satellite and radar data to determine parameters of the atmosphere and to detect extreme phenomena (e.g., forecasting the amount of precipitation or maximum wind speeds); diagnosis and forecasting of Poland's climate along with an assessment of changes under the influence of natural and anthropogenic factors; modeling of air pollution transport.

In the field of oceanology - research and forecasting of hydrological and meteorological conditions on the southern Baltic coast; improvement of measurement methods and chemical laboratory analyses used in testing the quality of marine waters.

(2-strong impact)

- Institute staff

The institute's strength is having qualified staff in the fields of meteorology, hydrology, climatology, computer science engineering and water management. It is a good basis for implementing the provisions of the $18^{\text {th }}$ Congress (2-strong impact).

\section{Weaknesses}

- Uncertainty of financial stability

Dangerous hydrological and meteorological phenomena are intensifying, indicating the need for optimal (from the point of view of the security of Poland and its inhabitants) development of the system for monitoring and forecasting of these phenomena by the National Hydrological and Meteorological Service. The implication is that sufficient funding must be restored to maintain this system and further develop it. It should be explained here that the reduction of PSHM funding in recent years (2014-2018) caused significant limitations on the collection of measurement and observation data on the state of the atmosphere and hydrosphere and their contribution to a central historical database, which has been kept by IMGWPIB since 1919. Further funding limitations may critically affect the effectiveness of research on climate change in Poland, international cooperation, and IMGW-PIB participation in related research projects. Moreover, ensuring minimum cooperation in connection with the new WMO organizational structure requires guaranteeing sound preparation and strengthening of the staff.. The development prospects for PSHM require the stabilization of IMGW-PIB financing as soon as possible, especially in the field of PSHM. Stabilization of financing will require restoring the full amount of funding defined in the applica- 
tions for co-financing of PSHM submitted by IMGW-PIB in previous years and maintaining it predictably thus enabling planning of activities and investments in the long term (at least several years) (2-strong impact).

- Status of implementation and management of the WMO-WIGOS program

Another challenge for PSHM will be full implementation of WMO-WIGOS (WMO Integrated Global Observing System), occupying one of the key places among the WMO activity development plans for the coming years. The goal of the system is to support initiatives taken as part of WMO, e.g., GAW - Global Atmosphere Watch. As part of the WIGOS system, it is assumed that PSHM will provide a coordinated and comprehensive observation system that economically and sustainably provides WMO members with data for the development of weather forecasts, climate change, water resources, and environmental observations. Expectations for the WIGOS system are directed toward timely, long-term series of measurement and observation data of appropriate quality, subject to quality control, and well documented.. The implementation of quality management procedures is required for better use of existing and future measurement and observation capabilities. It is crucial for national services to maintain the updated status of the network they manage in the OSCAR portal. It is also crucial in this case to properly identify all types of measurement platforms by applying and maintaining the appropriate WIGOS identifiers from the WSI (WIGOS Station Identifier) system. WSI is a system for assigning a unique identifier, applicable to all types of observation stations, irrespective of the owner, which allows registering a substantially unlimited number of stations in WIGOS. In many countries there are no standard identifiers in existing 5-digit allowed ranges and no additional stations can be registered. Implementation of the WSI is mandatory in accordance with WIGOS technical regulations. Only data from properly identified stations can be exchanged. In case there are platforms managed by institutions other than national services in a given country or region, the Congress has identified the possibility of not properly identifying such stations. To improve the process of assigning WSI, a Resolution was adopted enabling the relevant institutions (e.g., atmospheric chemistry monitoring agencies, etc.) to acquire relevant WIGOS IDs, except for the need to refer to relevant national services. The full integration of the observation network under the responsibility of the national services and the partner will not occur until the problem is resolved (1-weak impact).

\section{Opportunities}

- Modernization projects.

An extremely important factor that will affect the overall operation of IMGW-PIB including PSHM is the necessary modernization and development of the flood monitoring and warning system. As part of the loan financed by the World Bank, it assumes, among other things, a significant increase in the number of automatic measuring stations, modernization of measuring equipment currently used at PSHM stations, and modernization of field crew equipment. These steps will undoubtedly improve the effectiveness of the monitoring and warning system against dangerous hydrological and meteorological hazards. However, it will require an increase in the number of service employees and qualified staff servicing new devices, tech- 
nical solutions, and models. It will be necessary to improve the competence of the staff responsible for processing and analyzing data and results from numerical models to ensure high quality forecasts and warnings. In the longer term, organizational changes to enable optimal operation of existing and new infrastructure purchased as a result of the loan will also be considered (2-strong impact).

- Implementation of Global Basic Observing Network

The Congress adopted the concept of creating GBON, i.e. the Global Basic Observing Network, to secure an adequate, global-wide contribution of data to numerical forecasting systems. So far, not all associations can guarantee such a contribution. GBON is to become an operational network from July $1^{\text {st }}, 2021$. Considering e.g. the development of EUMETNET initiative METEOALARM, aimed at the exchanging of meteorological warnings, it seems that the European region is quite well prepared to implement the concept of GBON (1-weak impact).

- Cooperation with national air carrier

Great possibilities are inherent in the agreement initiated several months earlier between WMO and the International Air Transport Association (IATA). Under it, both institutions are to support IATA affiliated airlines in the development of the AMDAR system. Although it is another challenging task, the agreement opens the possibility of cooperation with the Polish national air carrier LOT Polish Airlines (1-weak impact).

\section{Threats}

- Need for appropriate financial expenditure regarding data policy

The progress in science and technology significantly improves our collective ability to generate decisionsupporting data, products and services for governments, businesses, and citizens. The Geneva Declaration adopted during the $18^{\text {th }}$ Congress encourages cooperation in the field of data exchange, emphasizing the importance of public-private partnership. Data from the Institute of Meteorology and Water Management, National Research Institute, are available via the ICT system at: http://dane.imgw.pl/ and at www.pogodynka.pl. Data that cannot be disclosed by the above methods can be provided upon request. The WMO Congress underlined the need for innovative approaches and incentives to enable fair and equitable access to data, including the rapidly accumulating non-traditional data from all sectors. Inevitably, approaching full openness in the field of data policy, as mandated by the amended EU Directive (Directive (EU) 2019/1024), will require appropriate financial expenditure and organizational solutions to ensure it.

Meeting this need will require, among other things:

a) Standardization and development of IT tools used in meteorological and hydrological protection as well as in the management, processing, and collection of hydrological and meteorological information.

b) Development of IT systems used to make data available to the public (e.g., dane.imgw.pl portal, SOK - Customer Service System or IMGW-PIB Monitor - the portal visualizing the operational meteorological and hydrological data). 
c) Improvement and development of meteorological and hydrological information forms, along with standardized publication of observation results measurements, and statistical studies as part of international exchange in accordance with WMO standards (data replicator from IMGW-PIB database resources to the OSCAR/Surface platform according to technical requirements outlined by WMO - as part of WIGOS). (1-weak impact).

- The ability to provide and finance high qualified staff for new tasks

Modernization projects will require an increase in the number of service employees and qualified staff servicing new devices, technical solutions, and models. These are usually very narrow specializations in which it is difficult to find specialists. It will be necessary to improve the competence of the staff responsible for processing and analyzing data and results from numerical models in order to ensure high quality forecasts and warnings. In the longer term, organizational changes to enable optimal operation of existing and new infrastructure purchased because of the modernization will also be considered. (2-strong impact).

\section{Conclusions}

The World Meteorological Congress adopted dozens of international law acts that set the framework for national services. In view of the fundamental changes in the management structure at WMO, the Polish National Meteorological and Hydrological Service will have to reconsider its contribution to the development of WMO by appointing relevant, competent representatives to the newly established Technical Commissions. The Congress has reformulated the means of developing and implementing many international, regional, and national processes that frame the activities of the national services. The reform process is scheduled for the next dozen or so months, during which time several important sessions will take place, in which active participation is a key task of the Polish service.

The following conclusions and recommendations are derived from the SWOT analysis:

- It is necessary to take advantage of the opportunities associated with modernization projects, which will strengthen the position and contributions of IMGW-PIB in Disaster Risk Reduction.

- IMGW-PIB financial stability and long-term sustainability of financing will ensure the ability to recruit and finance highly qualified staff for new tasks.

- Implementation and management of the WMO-WIGOS program will allow for better IMGW-PIB communication in various areas of WMO operations.

The opportunities resulting from the organizational structure and tasks performed by the Polish service in the fields of hydrology, meteorology, and related research works should be maximized. Finally, it is worth emphasizing that the unpredictable events associated with the COVID-19 pandemic can have a significant impact on the financing of hydro-met services, and may also have impacts on modernization and the organization of work. 


\section{Bibliography}

Convention, 1947, Konwencja dotycząca Światowej Organizacji Meteorologicznej podpisana w Waszyngtonie dnia 11 października 1947 r. ratyfikowana zgodnie z ustawą z dnia 30 grudnia 1949 roku

Directive (EU) 2019/1024 of the European Parliament and of the Council of 20 June 2019 on open data and the re-use of public sector information, EUR-Lex, Brussels

Directive 2000/60/EC of the European Parliament and of the Council of 23 October 2000 establishing a framework for Community action in the field of water policy, Official Journal L 327, 22/12/2000 P. 0001 - 0073, EUR-Lex, Brussels

GWP, 2011, Global Water Partnership Central and Eastern Europe, 2011, What is IWRM?, available online at https://www.gwp.org/en/GWP-CEE/about/why/what-is-iwrm/ (data access 02.08.2019)

Hyogo, 2007, United Nations International Strategy for Disaster Reduction, Hyogo Framework for Action 2005-2015, Geneva, Switzerland 2007, available online at https://www.unisdr.org/we/inform/publications/1037 (data access 09.08.2019)

ICAO, 2016, 2016-2030 Global Air and Navigation Plan, International Civil Aviation Organization, Montreal, Quebec, Canada, available online at https://www.icao.int/airnavigation/Documents/GANP-2016-interactive.pdf (data access 10.08.2019)

IMGW-PIB, 2016, Metody kontroli jakości dla polskiej Państwowej Służby Hydrologiczno-Meteorologicznej, vol. 9, IMGW-PIB, Warszawa

Szałata L., Zwoździak J., 2011, SWOT analysis as a basic tool in environmental management (in Polish), Rocznik Ochrona Środowiska, 13 (2), 1105-1113

Water Law, 2017, Ustawa z dnia 20 lipca 2017 r. Prawo Wodne, Dz.U. z 2017 r. poz. 1566, 2180, z 2018 r. poz. 650, 710 